\title{
THE EFFECTS OF ACUTELY INCREASED SYSTEMIC RESIST- ANCE ON THE LEFT ATRIAL PRESSURE PULSE: A METHOD FOR THE CLINICAL DETECTION OF MITRAL INSUFFICIENCY
}

\author{
By EUGENE BRAUNWALD, G. H. WELCH, JR., AND ANDREW G. MORROW \\ (From the Laboratory of Cardiovascular Physiology and the Clinic of Surgery, National \\ Heart Institute, Bethesda, Md.)
}

(Submitted for publication August 14, 1957; accepted September 5, 1957)

In 1921, Wiggers and Feil in a study of experimental mitral insufficiency observed an elevation of left atrial pressure when the aorta was constricted (1). This finding has subsequently been confirmed both in experimental animals $(2,3)$ and in a circulatory model (4). In recent experiments "mitral" regurgitant flow was produced and measured by permitting blood to pass from the left ventricle through a flow meter into the left atrium (5). It was observed that with any given mitral regurgitant orifice the regurgitant flow could be substantially increased by elevating the resistance to left ventricular ejection with graded aortic constriction.

The experimental observations listed above suggested that acutely increased resistance to left ventricular ejection in patients with mitral regurgitation should also result in an elevation of left atrial pressure. It was further reasoned that such elevations of left atrial pressure would not occur in patients without mitral valve disease or with pure mitral stenosis and that this difference in response might therefore be of value in the clinical detection of mitral regurgitation. In addition to such observations in patients, it was considered desirable to determine the effects of elevated aortic pressure on the left atrial pressure pulse in animals before and after the production of experimental mitral regurgitation.

\section{EXPERIMENTAL OBSERVATIONS}

Methods. Dogs weighing 14.5 to $20.4 \mathrm{Kg}$. were studied with intravenous pentobarbital anesthesia and positive pressure respiration. The left chest was entered through the fifth intercostal space. A perforated tygon tube was placed into the left atrium through the appendage; by advancing the end of the tube through the mitral valve into the left ventricle mitral regurgitation was induced and could be abolished by withdrawal of the tube (Figure 1). Resistance to left ventricular ejec- tion was increased either by an infusion of norepinephrine ( $0.008 \mathrm{mg}$. per $\mathrm{ml}$. isotonic saline), or by means of graded constriction of the ascending aorta with an aneurysm clamp. Pressures were recorded from the left atrium and from the aorta proximal to the constriction. In two experiments a Potțer turbine flow meter (6) was introduced into the aorta for the continuous registration of systemic flow. All recordings were made on a multichannel oscillograph.

\section{RESULTS}

Results representative of 26 experiments performed in eight dogs are illustrated in the experiment shown in Figure 2A. In the absence of mitral regurgitation, striking elevations of aortic pressure raised the $\mathrm{v}$ point of the left atrial tracing relatively little. A degree of mitral insufficiency which produced only slight elevation of the $\mathrm{v}$ point was then induced. A striking elevation of the left atrial $v$ point occurred when aortic pressure was then raised by aortic constriction. This finding was consistent regardless of whether aortic pressure was elevated by aortic constriction or by norepinephrine infusion.

In two experiments systemic flow was recorded while norepinephrine was infused. A greater depression of systemic flow and greater elevation of left atrial mean and $\mathrm{v}$ point pressures occurred when mitral regurgitation was present than when absent.

\section{CLINICAL OBSERVATIONS}

Selection of patients and methods. A total of 20 patients has been studied. Group I consists of seven patients without mitral insufficiency, of whom six had "pure" mitral stenosis on the basis of clinical findings, the demonstration at left heart catheterization of a diastolic pressure gradient between left atrium and left ventricle, and by palpation of the valve at operation. The seventh patient in this group, J. T., had an atrial septal defect without associated mitral insufficiency; this diagnosis 


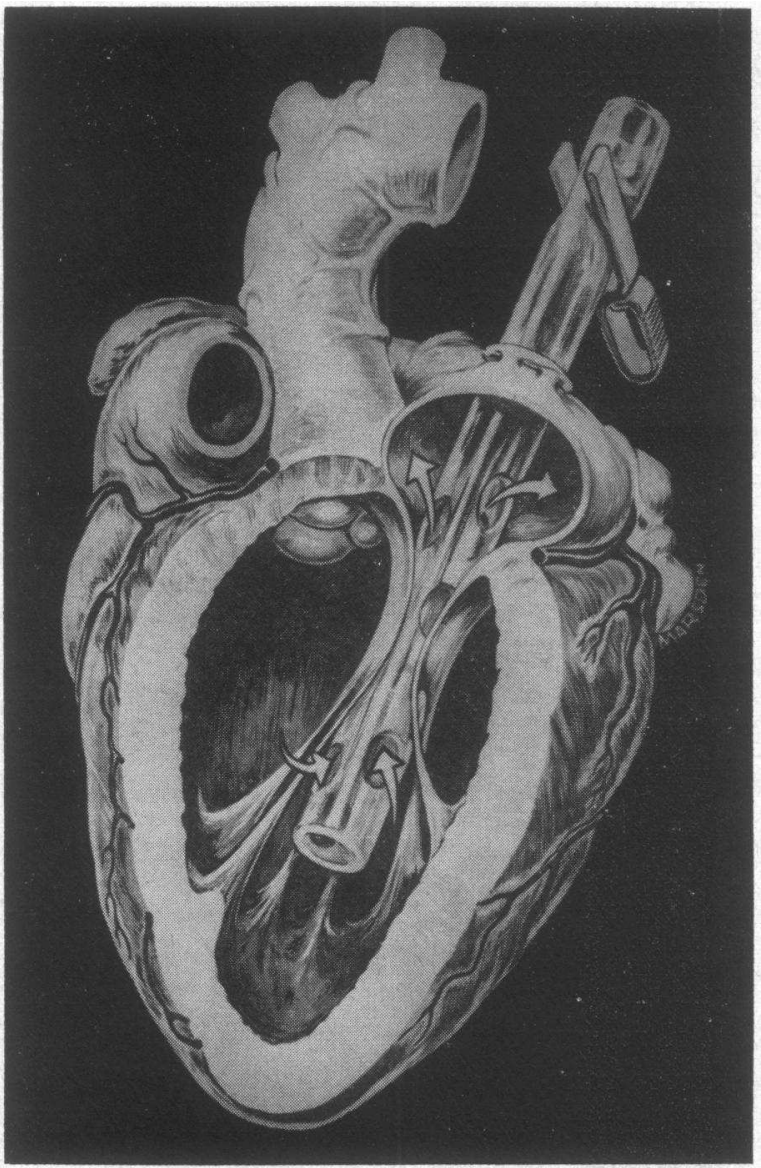

Fig. 1. Diagram of the Experimental Method of Production of Reversible Mitral Insuffiency

was confirmed at operation. Group II consists of thirteen patients with mitral insufficiency. The six patients in Subgroup IIA had mitral stenosis proved by the presence of a diastolic pressure gradient between left atrium

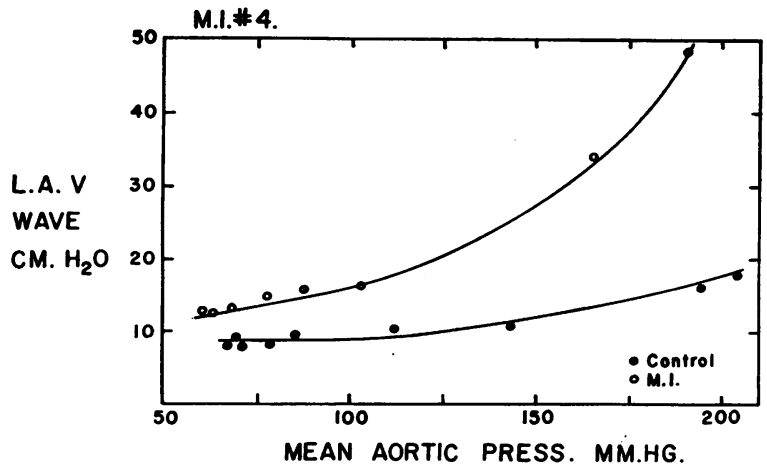

Fig. 2A. Relation Between Left Atrial $v$ Point Pressure and Mean Aortic Pressure in Dogs Before and After the Production of Mitral Insuffiency

Aortic pressure elevated by aortic constriction. and left ventricle and by operative findings, but in all of these patients a definite regurgitant jet was also palpable. The seven patients in Subgroup IIB presented the clinical picture of "pure" mitral insufficiency; the presence of a left to right shunt was excluded by right heart catheterization.

Left atrial pressures were measured by the technique of transbronchial left heart catheterization, which has been described in detail (7). In the first eight patients norepinephrine was infused while the bronchoscope was in place and left atrial pressure was recorded through the transbronchial needle. In the other twelve patients, following measurement of left ventricular pressure with a polyethylene catheter threaded through the transbronchial needle, both the bronchoscope and needle were removed and the catheter was left in situ. After a 20 to

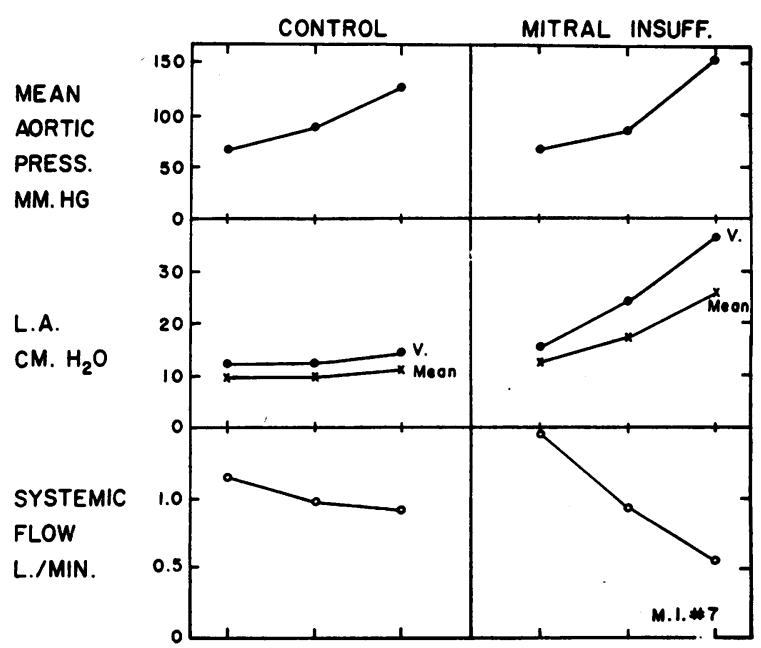

Fig. 2B. Alterations in Forward Systemic Flow Accompanying Elevation of Aortic Pressure Before and After the Production of Mitral Insufficiency

Aortic pressure elevated by norepinephrine infusion.

30 minute period during which the patient returned to a more basal state, the catheter was withdrawn into the left atrium and the norepinephrine then infused.

In the measurement of left atrial pressures, a Statham P23 A strain gauge was employed with the transbronchial needle, and a P23 D gauge with the polyethylene catheter. Left atrial and systemic arterial pressures and the electrocardiogram were continuously recorded and visually monitored on a multichannel photographic recorder.

Following control observations, norepinephrine was infused at approximately 10 to $20 \gamma$ per minute. The infusion was continued until systolic arterial pressure became significantly elevated (approximately three to five minutes). The infusion was then stopped and measurements continued until the arterial pressure returned to control levels. Pressure measurements were averaged over two respiratory cycles. Mean pressures were obtained either by electrical or planimetric integration. 
TABLE I

Hemodynamic observations before and during norepinephrine infusion

\begin{tabular}{|c|c|c|c|c|c|c|c|c|c|c|c|}
\hline \multirow[b]{3}{*}{ Patient } & \multicolumn{5}{|c|}{ Before norepinephrine infusion* } & \multicolumn{5}{|c|}{ During norepinephrine infusion } & \multirow{3}{*}{$\frac{\text { Elevation L. A. } v \times 100}{\text { Elevation F. A. syst. }}$} \\
\hline & \multicolumn{2}{|c|}{ F. A. } & \multicolumn{2}{|c|}{ L. A. } & \multirow{2}{*}{$\underset{\text { rate }}{\text { Heart }}$} & \multicolumn{2}{|l|}{ F. A. } & \multicolumn{2}{|c|}{ L. A. } & \multirow{2}{*}{$\underset{\text { reart }}{\text { rate }}$} & \\
\hline & $\mathrm{s} / \mathrm{d}$ & $\mathrm{m}$ & $\mathrm{v}$ & $\mathrm{m}$ & & $s_{i}^{\prime} d$ & $\mathrm{~m}$ & $\mathrm{v}$ & $\mathrm{m}$ & & \\
\hline \multicolumn{12}{|c|}{ Group I-No mitral insufficiency } \\
\hline $\begin{array}{l}\text { D. G. }{ }^{\dagger} \\
\text { D. S. } \dagger \\
\text { I. IV. } \\
\text { J. G. } \\
\text { B. C. } \\
\text { J. B. } \dagger \\
\text { J. T. }\end{array}$ & $\begin{array}{r}114 / 54 \\
138 / 61 \\
80 / 46 \\
136 / 68 \\
104 / 55 \\
124 / 66 \\
116 / 77\end{array}$ & $\begin{array}{l}76 \\
93 \\
60 \\
91 \\
78 \\
80 \\
88\end{array}$ & $\begin{array}{l}34 \\
12 \\
13 \\
10 \\
19 \\
22 \\
10\end{array}$ & $\begin{array}{r}29 \\
9 \\
14 \\
10 \\
19 \\
19 \\
8\end{array}$ & $\begin{array}{r}96 \\
64 \\
100 \\
76 \\
80 \\
88 \\
68\end{array}$ & $\begin{array}{l}156 / 79 \\
186 / 73 \\
166 / 67 \\
164 / 75 \\
163 / 72 \\
151 / 58 \\
172 / 88\end{array}$ & $\begin{array}{r}104 \\
113 \\
116 \\
103 \\
100 \\
98 \\
120\end{array}$ & $\begin{array}{l}36 \\
22 \\
15 \\
14 \\
23 \\
23 \\
14\end{array}$ & $\begin{array}{l}25 \\
14 \\
22 \\
13 \\
21 \\
19 \\
11\end{array}$ & $\begin{array}{l}40 \\
50 \\
64 \\
60 \\
68 \\
50 \\
52\end{array}$ & $\begin{array}{r}5 \\
21 \\
2 \\
14 \\
7 \\
4 \\
7\end{array}$ \\
\hline \multicolumn{12}{|c|}{ Group IIA-Mitral insufficiency and stenosis } \\
\hline $\begin{array}{l}\text { E. C. } \dagger \\
\text { J. M. }{ }^{\dagger} \\
\text { G. S. } \\
\text { E. P. } \\
\text { N. M. } \dagger \\
\text { H. C. } \dagger\end{array}$ & $\begin{array}{l}133 / 72 \\
123 / 49 \\
128 / 75 \\
151 / 74 \\
179 / 78 \\
128 / 64\end{array}$ & $\begin{array}{r}91 \\
84 \\
91 \\
102 \\
109 \\
81\end{array}$ & $\begin{array}{l}10 \\
10 \\
38 \\
33 \\
26 \\
25\end{array}$ & $\begin{array}{r}9 \\
5 \\
35 \\
23 \\
20 \\
16\end{array}$ & $\begin{array}{r}104 \\
60 \\
92 \\
104 \\
58 \\
72\end{array}$ & $\begin{array}{l}182 / 91 \\
206 / 78 \\
163 / 88 \\
200 / 80 \\
225 / 85 \\
181 / 79\end{array}$ & $\begin{array}{l}122 \\
110 \\
110 \\
123 \\
132 \\
128\end{array}$ & $\begin{array}{l}14 \\
35 \\
47 \\
58 \\
38 \\
42\end{array}$ & $\begin{array}{l}11 \\
21 \\
41 \\
34 \\
25 \\
23\end{array}$ & $\begin{array}{r}68 \\
40 \\
100 \\
80 \\
68 \\
68\end{array}$ & $\begin{array}{r}8 \\
30 \\
26 \\
51 \\
26 \\
32\end{array}$ \\
\hline \multicolumn{12}{|c|}{ Group IIB-Pure mitral insufficiency } \\
\hline $\begin{array}{l}\text { L. G. } \dagger \\
\text { J. L. } \dagger \\
\text { M. S. } \dagger \\
\text { W. B. } \\
\text { K. S. } \\
\text { W. C. } \\
\text { M. T. } \dagger\end{array}$ & $\begin{array}{r}134 / 77 \\
98 / 60 \\
131 / 71 \\
127 / 76 \\
135 / 69 \\
111 / 67 \\
167 / 91\end{array}$ & $\begin{array}{r}103 \\
76 \\
92 \\
94 \\
95 \\
87 \\
122\end{array}$ & $\begin{array}{r}20 \\
21 \\
3 \\
12 \\
38 \\
48 \\
32\end{array}$ & $\begin{array}{r}13 \\
19 \\
3 \\
10 \\
17 \\
28 \\
24\end{array}$ & $\begin{array}{l}96 \\
66 \\
96 \\
84 \\
88 \\
96 \\
72\end{array}$ & $\begin{array}{l}198 / 105 \\
128 / 79 \\
184 / 105 \\
187 / 89 \\
203 / 91 \\
146 / 83 \\
197 / 104\end{array}$ & $\begin{array}{r}134 \\
97 \\
126 \\
120 \\
148 \\
102 \\
152\end{array}$ & $\begin{array}{l}45 \\
36 \\
31 \\
35 \\
92 \\
92 \\
48\end{array}$ & $\begin{array}{l}26 \\
30 \\
13 \\
20 \\
42 \\
46 \\
32\end{array}$ & $\begin{array}{l}65 \\
52 \\
72 \\
64 \\
77 \\
92 \\
80\end{array}$ & $\begin{array}{r}39 \\
50 \\
53 \\
38 \\
79 \\
126 \\
53\end{array}$ \\
\hline
\end{tabular}

* F. A., femoral artery pressure; L. A., left atrial pressure; s, systolic; d, diastolic; m, mean; v, v point pressures. All pressures are in $\mathrm{mm}$. $\mathrm{Hg}$.

$\dagger$ Observations made 20 to 30 minutes following bronchoscopy.

\section{RESULTS}

The majority of the patients described a brief sensation of pounding in the chest and head accompanying the norepinephrine infusion. Several patients developed occasional premature ventricular contractions during the infusion and one had a brief period of bigeminal rhythm. No complications resulted from the left heart catheterizations.

The results of the clinical studies are summarized in Table I. In the patients without mitral regurgitation (Group I) only a slight elevation of left atrial pressure occurred as systolic arterial pressure was raised (Figures 3 and 4 ). The ratio of the elevation of the left atrial $\mathrm{v}$ point pressure to the rise in systemic arterial systolic pressures ranged from 2 to 21 per cent, averaging 9 per cent. In contrast, in all but one of the patients with mitral regurgitation (Group II) a substantial rise in left atrial pressure occurred as systemic pressure was elevated (Figures 3 and 5 ). The ratio of the elevation of the left atrial $\mathrm{v}$ point pressure to the rise in systemic arterial systolic pressure ranged from 8 to 126 per cent, averaging 47 per cent. In all but one of these patients (E. C.), this ratio exceeded the highest ratio obtained in patients without mitral insufficiency. The ratios tended to be lower in the patients with combined mitral stenosis and insufficiency (Group IIA) than in the patients with pure mitral insufficiency (Group IIB). In Group IIA the ratios ranged from 8 to 51 per cent, with an average of 30 per cent, while in Group IIB the range was from 38 to 126 per cent, with an average of 63 per cent.

\section{DISCUSSION}

When norepinephrine is infused in the absence of mitral insufficiency, left atrial pressure is increased only slightly. The stroke work of the left ventricle is increased by both the elevation of aortic pressure and by the bradycardia. The increase in left ventricular stroke work elevates left ventricular end-diastolic and left atrial pres- 


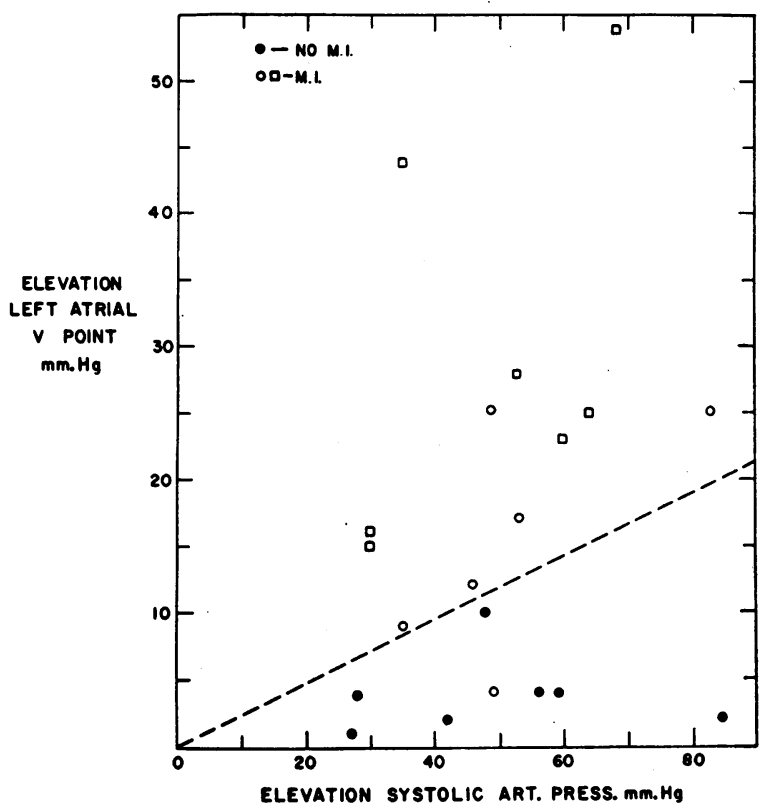

Fig. 3. Relationship of Elevation of Left Atrial v Point Pressure to Elevation of Femoral Arterial Systolic Pressure in Patients With and Without Mitral InSUFFicienCy

Closed circles represent patients without mitral insufficiency; open circles, patients with mitral stenosis and insufficiency; open squares, patients with pure mitral insufficiency.

sure (8). However, the elevation of the left ventricular function curve by norepinephrine (9) acts in the opposite direction and tends to decrease left atrial pressure. When mitral insufficiency is present, norepinephrine also increases the systolic pressure gradient across the regurgitant orifice and thereby results in increased mitral regurgitant flow and a substantially greater increase in left atrial pressure. In the dogs in which forward systemic flow was metered (Figure $2 \mathrm{~b}$ ) this elevation of left atrial pressure was accompanied by a fall in forward cardiac output. Other experiments on metered mitral regurgitant flow have shown that total cardiac output, i.e., the sum of regurgitant flow and forward cardiac output, remains relatively constant as forward cardiac output and regurgitant flow vary reciprocally with aortic constriction (5). Thus, in the presence of mitral regurgitation, if left ventricular emptying across the aortic valve is hindered, the blood seeks the other path available to it and mitral regurgitant flow is increased.

It would seem to follow that with any given regurgitant orifice, any mechanism operating to increase the left venrticular systolic pressure, such as systemic hypertension or aortic stenosis, would augment mitral regurgitant flow, Similarly, when ventricular systolic pressure is elevated by aortic insufficiency, coexistent mitral regurgitation is poorly tolerated $(10,11)$.

Norepinephrine was the agent chosen to increase peripheral resistance acutely because its effects are transient and the arterial pressure level could therefore be precisely controlled by the speed of infusion. Since it is well recognized that this drug increases myocardial contractility as well as peripheral resistance $(9,12)$, it is likely that

\section{B.C., M.S.}

CONTROL

DURING N.E. INFUSION

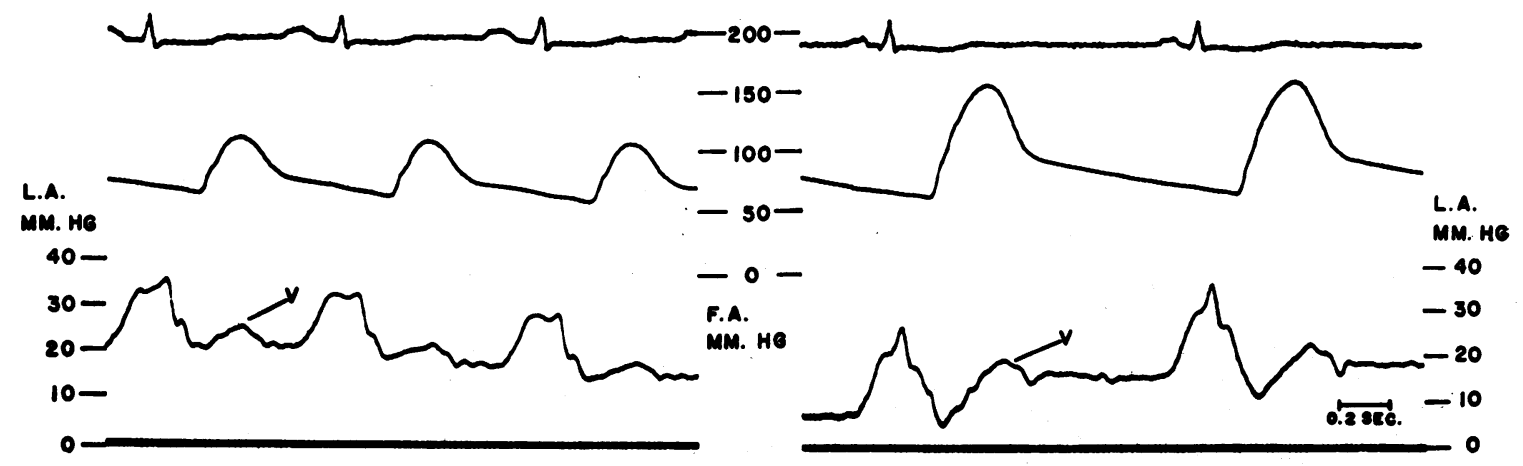

Fig. 4. Femoral Arterial (F.A.) and Left Atrial (L.A.) Pressures Before and During Norepinephrine (N.E.) Infusion in Patient B. C. with Pure Mitral Stenosis 


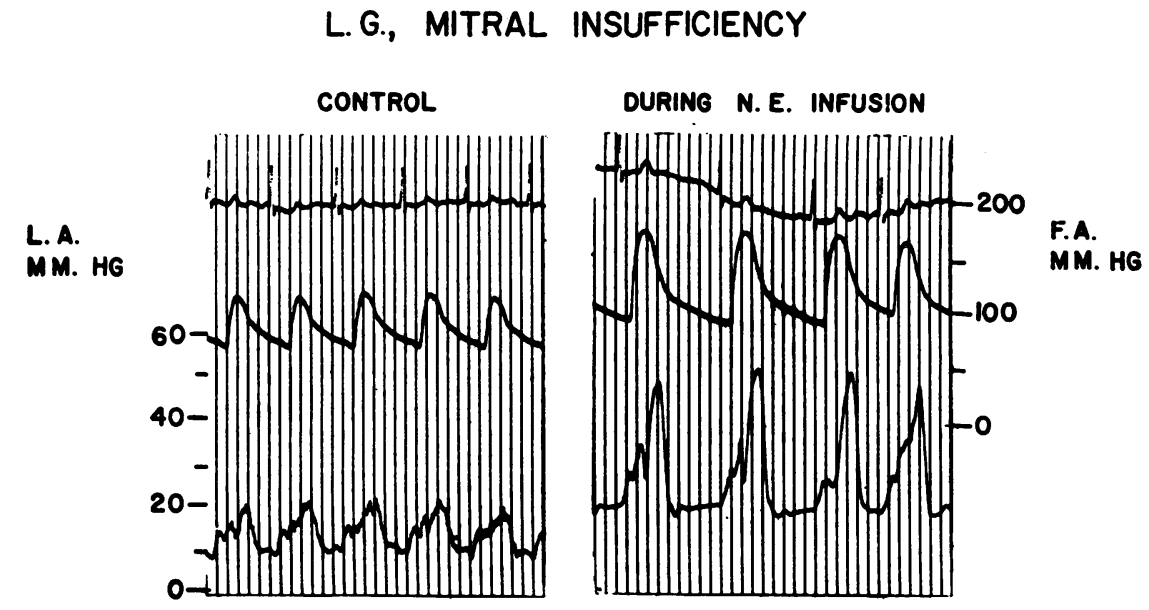

Fig. 5. Femoral Arterial and Left Atrial Pressures in Patient L. G. With Pure Mitral Insufficiency

Vertical time lines indicate 0.1 second.

if an agent such as methoxamine, which acts predominantly on the periphery, had been employed the elevation of atrial pressure would have been greater in both groups of patients.

The extent to which left atrial pressure is elevated during norepinephrine infusion would appear to be of diagnostic value. The presence of severe, pure mitral insufficiency can generally be recognized in the left atrial pressure tracing (13). When mitral regurgitation is associated with mitral stenosis, the pressure pulse is modified and sometimes is indistinguishable from that obtained in patients with "pure" stenosis. However, in the present study, the elevation of arterial pressure resulted in greater elevation of left atrial pressure in patients with combined mitral stenosis and insufficiency than in patients with "pure" mitral stenosis. Therefore, the technique described affords opportunity for the detection of mitral insufficiency in patients with associated mitral stenosis.

Patients who present apical systolic murmurs without elevation of left atrial pressure may present difficult diagnostic problems. While an elevated left atrial $\mathrm{v}$ point may suggest the presence of mitral regurgitation, it should be emphasized that this point is often the highest in the left atrial pressure pulse during the cardiac cycle in normal man (14). The effect on left atrial pressure of increasing resistance to aortic ejection may be of value in establishing or excluding the presence of mitral insufficiency in such patients.

\section{SUMMARY}

The effects of increased resistance to ventricular ejection on the left atrial pressure pulse were studied in eight dogs with reversible mitral insufficiency. In the absence of mitral insufficiency, elevated aortic pressure resulted in only slight elevations in the left atrial $\mathbf{v}$ point. Similar increases in aortic pressure in the presence of mitral insufficiency resulted in striking elevations of mean and $\mathrm{v}$ point pressures.

Utilizing the techniques of transbronchial left heart catheterization and norepinephrine infusion, similar observations were made in 20 patients. In the absence of mitral insufficiency (seven patients) the average ratio of increase of $v$ point pressure to increase in systolic peripheral arterial pressure was only 9 per cent. In contrast, in 13 patients with mitral insufficiency this ratio averaged 47 per cent. Although the highest ratios were observed in patients with "pure" mitral insufficiency, striking increases in left atrial pressure were seen in patients with both mitral stenosis and insufficiency. The physiologic mechanisms involved and the usefulness of this technique in the clinical recognition of mitral insufficiency are discussed.

\section{REFERENCES}

1. Wiggers, C. J., and Feil, H., The cardio-dynamics of mitral insufficiency. Heart, 1922, 9, 149.

2. Crawshaw, G. R., Wilson, V. H., Kreel, L., Vetten, K. B., and Borman, J. B., Experimental mitral 
incompetence in dogs: Studies in haemodynamics. Brit. J. Surg., 1954, 42, 319.

3. Moscovitz, H. L., and Wilder, R. J., The pressure events of the cardiac cycle in the dog: mitral valve lesions. Am. Heart J., 1957, 53, 741.

4. Rodbard, S., and Williams, F., The dynamics of mitral insufficiency. Am. Heart J., 1954, 48, 521.

5. Braunwald, E., Welch, G. H., Jr., and Sarnoff, S. J., The hemodynamics of quantitatively varied experimental mitral regurgitation. Circ. Research, 1957, 5, 539.

6. Sarnoff, S. J., and Berglund, E., The Potter electroturbinometer; An instrument for recording total systemic flow in the dog. Circ. Research, 1953, $1,331$.

7. Morrow, A. G., Braunwald, E., Haller, J. A., Jr., and Sharp, E. H., Left heart catheterization by the transbronchial route: Technique and applications in physiologic and diagnostic investigations. Circulation. In press.

8. Sarnoff, S. J., and Berglund, E., Ventricular function I. Starling's law of the heart studied by means of simultaneous right and left ventricular function curves in the dog. Circulation, 1954, 9, 706.
9. Welch, G. H., Jr., Braunwald, E., Case, R. B., and Sarnoff, S. J., The effect of mephentermine sulfate (Wyamine ${ }^{\circledR}$ ) on myocardial oxygen consumption, myocardial efficiency and peripheral vascular resistance. Am. J. Med. In press.

10. Roshe, J., Haller, J. A., Jr., and Morrow, A. G., Combined aortic and mitral insufficiency-hemodynamic effects of the Hufnagel valve. Ann. Surg., 1956, 144, 854.

11. Welch, G. H., Jr., Braunwald, E., and Sarnoff, S. J.,

- The hemodynamic effects of quantitatively varied experimental aortic regurgitation. Circ. Research, 1957, 5, 546.

12. Goldberg, L. I., Cotten, M. de V., Darby, T. D., and Howell, E. V., Comparative heart contractile force effects of equipressor doses of several sympathomimetic amines. J. Pharmacol \& Exper. Therap., 1953, 108, 177.

13. Morrow, A. G., Braunwald, E., Haller, J. A., Jr., and Sharp, E. H., The left atrial pressure pulse in mitral valve disease. A correlation of pressures obtained by transbronchial puncture with the valvular lesion. Circulation, 1957, 16, 399.

14. Braunwald, E., Fishman, A. P., and Cournand, A., Time relationship of dynamic events in the cardiac chambers, pulmonary artery, and aorta in man. Circ. Research, 1956, 4, 100. 